\title{
THE INFLUENCE OF MEHCANICAL RECYCLING ON THE MECHANICAL AND THERMAL PROPERTIES OF THERMOTROPIC LIQUID CRYSTALLINE POLYMER AND GLASS FIBER REINFORCED POLYPROPLYENE
}

\author{
Tianran Chen and Donald G. Baird \\ Macromolecules Innovation Institute and Department of Chemical Engineering, Virginia Tech, \\ Blacksburg, VA 24061
}

\begin{abstract}
In this paper, high-performance thermotropic liquid crystalline polymer (TLCP)/polypropylene (PP) and glass fiber (GF)/PP composites were prepared by the injection molding process. Mechanical recycling of TLCP/PP and GF/PP composites consisted of grinding of the injection molded specimens and further injection molding of the granules. The influence of mechanical recycling on mechanical and thermal properties was investigated. In situ TLCP/PP maintains tensile modulus and strength during the recycling process, indicating the regeneration of polymeric fibrils at each reprocessing stage. GF/PP composite exhibits deterioration of mechanical properties after recycling because of fiber breakage during processing, which is a very common issue on reusing glass or carbon fiber reinforced composites. The experimental results reveal that the TLCP/PP composite has better recyclability than GF/PP.
\end{abstract}

\section{Introduction}

A conventional composite is composed of two or more distinct materials to produce a combination with structure properties that are not present in any individual component. Fiber-reinforced thermoplastic composites consist of dispersed reinforcement embedded in a continuous matrix phase. The applications of fiber-reinforced composite materials in automotive, aerospace and construction industries are rapidly emerging because of their lightweight, great mechanical performance and corrosion resistance[1]. Glass fiber, which dominated the overall market of fiber composites, combined with thermoplastic matrices to enhance the strength, stiffness and impact strength of the blend. Polypropylene resin is widely used in packaging, household product and especially as a matrix material in composites, due to the ease of processing associated with the low manufacturing cost.

The increasing use of fiber-reinforced thermoplastic composites has raised the environmental and economic awareness. One of the biggest challenges imposed by using these composites is their recyclability. The traditional way (incineration and landfill) to manage the composite wastes already exerted negative impact on environment. The increasing accumulated plastic wastes accelerate the urgency to develop recycling methods and recyclable materials[2].

Thermotropic liquid crystalline polymers (TLCPs) as another reinforcement provide high mechanical properties, light weight (almost half density of glass fiber), better recyclability and great chemical resistance [3-11]. The highest mechanical properties of TLCPs usually are achieved by fiber spinning where the tensile strength has been reported over $1 \mathrm{GPa}$ and tensile modulus up to 100 $\mathrm{GPa}[12]$, which are competitive with mechanical properties of glass fiber (strength 1-2 GPa, Modulus 69-83 $\mathrm{GPa}[13])$.

Mechanical recycling consists of grinding materials into the small particulates and reuse the ground composites for the reinforcement or filler. The incorporation level of the reinforcement/filler is limited to $10 \mathrm{wt} \%$ due to the deterioration in mechanical properties[14]. High fiber attrition during the grinding and the process of generation of plastic parts restricts the wide application of mechanical recycling for the conventional fiber composites[15]. Unlike conventional fiber, TLCPs are capable of forming extended molecular conformations when subjected to extensional or shear stress. TLCPs generate the highly oriented polymeric fibrils during the composite generation processes (mold filling step in injection molding) and avoid fiber breakage issue. In this work, the authors seek to develop a recyclable and high-performance TLCP/PP composite and compare the effect of mechanical recycling on mechanical and thermal properties between TLCP/PP and GF/PP [16].

\section{Experimental}

\section{Materials and Processing Methods}

The thermotropic liquid crystalline polymer used for this study is Vectra B950 (VB), which is a copolyesteramide with 6-hydroxy-2-naphtoic acid (60 $\mathrm{mol} \%)$, terephthalic acid (20 mol\%) and aminophenol (20 mol\%). Vectra B950 has a melting point around $280^{\circ} \mathrm{C} .50$ $\mathrm{wt} \%$ of glass fiber reinforced polypropylene was used and initial fiber length is around $8 \mathrm{~mm}$. Injection molding grade polypropylene with a commercial name Pro-fax 6523 was obtained from LyondellBasell. Maleic-anhydride-grafted polypropylene (MAP) was provide by Chemtura. MA-PP is well known to enhance interfacial strength between TLCP and PP[17]. 
The pellets of GF/PP, VB, PP and MAP were dried in a vacuum oven at $80^{\circ} \mathrm{C}$ for at least 24 hours. The reinforcement was maintained at $50 \mathrm{wt} \%$ for both GF/PP and VB/PP/MAP. GF/PP was injection molded into endgate plaques. A granulator was used to shred the injection molded plaques into fine particulates. The particulates of GF/PP were dried in a vacuum oven before injection molding. This process was repeated three times and each reprocessing cycle is designated as R-0, R-1, R-2 and R3. Samples were randomly selected from recycled materials for mechanical and thermal characterization. The mechanical recycling of VB/PP/MAP was carried out in the same recycling scheme (injection molding and grinding) and 20wt\% MAP was blende with PP and VB in a single screw extruder at $290^{\circ} \mathrm{C}$.

\section{Characterizations and Measurements}

ARES-G2 (TA Instruments) rheometer was used to analyze the thermal stability of PP at 250, 260, 270, 280, 290 and $300^{\circ} \mathrm{C}$ with small amplitude oscillatory time sweep mode. PP was dried in a vacuum oven at $80^{\circ} \mathrm{C}$ for 24 hours before use. Pellets were loaded between $25 \mathrm{~mm}$ diameter parallel plate fixtures at various temperature under nitrogen.

The tensile specimens ( $75 \mathrm{~mm} * 8 \mathrm{~mm}$ rectangular strip) were cut along the flow and transverse directions from the end-gate plaques. All tensile properties were measured by Instron Mechanical Tester (Model 4204) with $5 \mathrm{kN}$ load cell. Crosshead speed was maintained at $1.27 \mathrm{~mm} / \mathrm{min}$ and the deformation of specimens was measured with extensometer

Thermal properties of recycled VB/PP/MA-PP and GF/PP were examined by a differential scanning calorimetry (DSC). Under the nitrogen atmosphere, about $5 \mathrm{mg}$ samples were subjected to heat/cool/heat cycle at $10^{\circ} \mathrm{C} / \mathrm{min}$ ramp rate. Samples were first equilibrated at $30^{\circ} \mathrm{C}$ for $5 \mathrm{~min}$ and then heated to $250^{\circ} \mathrm{C}$. The materials were cooled down to $-50^{\circ} \mathrm{C}$, and then heated back up to $250^{\circ} \mathrm{C}$. The glass transition temperature $\left(T_{\mathrm{g}}\right)$, melting temperature $\left(T_{\mathrm{m}}\right)$, and enthalpy of melting $\left(\Delta H_{\mathrm{m}}\right)$ were determined using the TROIS software (TA Instruments).

To characterize the fiber attrition of recycled composite, the matrix of the composite was burned off in a oven at $500^{\circ} \mathrm{C}$, and a mat of glass fibers remains. More than 1000 glass fibers of each specimen were measured. Details of fiber length measurement procedure is described in the Ref[18]. The number average $\left(L_{n}\right)$ and weight average $\left(L_{w}\right)$ fiber length of the recycled GF composite were calculated and listed in Table 2.

\section{Results and Discussion}

\section{Thermal Stability of PP}

To generate in situ VB/PP composites, the thermal stability of PP at elevated temperature must be examined.
In situ $\mathrm{VB} / \mathrm{PP}$ composites have been processed by other researchers with the processing temperature from 285 to $300{ }^{\circ} \mathrm{C}[19,20]$. The parallel plate rheometer was operated in the time sweep mode to record the change of complex viscosity with time. The residence time of the injection molding process is around $180 \mathrm{~s}$. The overall residence time is around $720 \mathrm{~s}$, because the composites have been injection molded four times. At the temperature of $300{ }^{\circ} \mathrm{C}$, the complex viscosity of PP decreases around 52\% in 720 $\mathrm{s}$ which may result in significant thermal degradation of propylene, as shown in Figure 1. It also can be seen that the rate of decrease of the complex viscosity at $300{ }^{\circ} \mathrm{C}$ is much more rapid than 280 and $290{ }^{\circ} \mathrm{C}$. Therefore, $290{ }^{\circ} \mathrm{C}$ is selected for blending PP with VB in order to minimize the thermal degradation of polypropylenel.

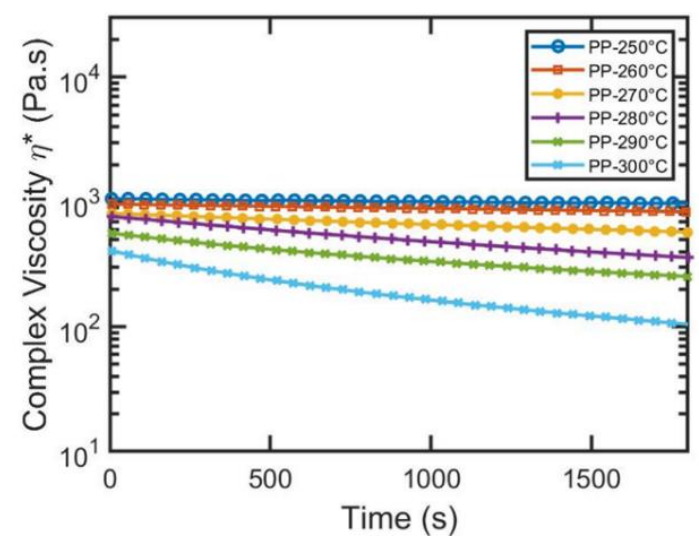

Figure 1. The change of complex viscosity as time at various temperatures

\section{Tensile Properties of Recycled Composites}

The tensile modulus and strength of the first injection molding VB/PP/MAP, VB/PP, GF/PP, VB and PP in flow direction are presented in Table 1. Both GF and VB, as the reinforcement, have significantly increased the tensile properties of $\mathrm{PP}$. VB/PP/MAP enhances the tensile modulus and strength of $\mathrm{PP}$ by 6.4 and 2.6 times, respectively. $7.65 \mathrm{GPa}$ is predicated by rule-of-mixture of the modulus of $50 \mathrm{wt} \% \mathrm{VB} / \mathrm{PP}$. The measured tensile modulus of VB/PP shown in Table 1 is very close to the theoretical limit which indicates generation of a strong composite and a good adhesion of VB/PP blend. By adding MAP, tensile modulus and tensile strength of the VB/PP composite are improved by $11 \%$ and $19 \%$, respectively. The enhancement in tensile properties by adding MAP into TLCP/thermoplastic blend has also been observed by other investigators[21, 22]. Acting as a surfactant, MAP reduces the interfacial tension which will result in a better adhesion and dispersion in the blend and improves the mechanical properties[23].

Table 2. Tensile Properties of injection molded 


\begin{tabular}{ccc}
\hline Polymer & Modulus (GPa) & Strength $(\mathrm{MPa})$ \\
\hline VB/PP/MAP & 7.9 & 53.9 \\
VB/PP & 7.1 & 43.9 \\
GF/PP & 7.9 & 82.3 \\
VB & 17.5 & 130.5 \\
PP & 1.2 & 20.5 \\
\hline
\end{tabular}

The injection molded end-gate plaques provide more information of mechanical properties in flow and transverse directions than tensile bars. Mechanical performance of recycled VB/PP/MAP and GF/PP in flow direction are summarized in Figure 2 and 3. VB/PP/MAP sustains tensile modulus and strength during three recycling cycles. During molding filling, the elongation flow occurs at the melt front (fountain flow) and can induce high molecular orientation in the flow direction. The generation of highly oriented TLCP fibers during elongation flow enables similar mechanical performance at each recycling stage and avoids the fiber breakage issue.

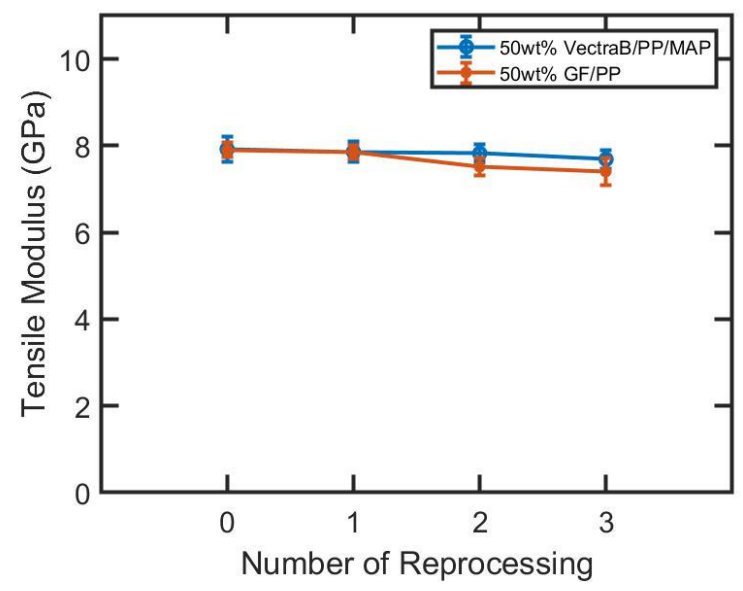

Figure 2. Tensile modulus of recycled VB/PP/MAP and $\mathrm{GF} / \mathrm{PP}$ in flow direction

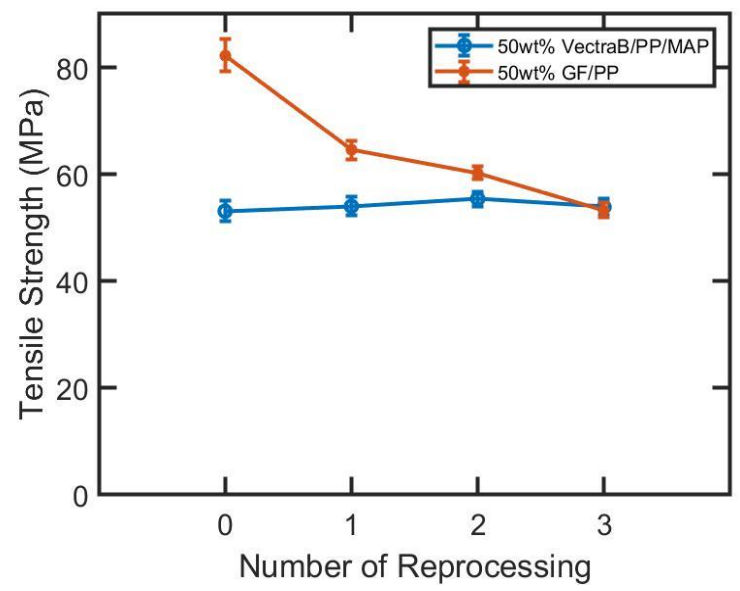

Figure 3. Tensile strength of recycled VB/PP/MAP and GF/PP in flow direction
For glass fiber composite, the mechanical recycling had tremendous effect on tensile strength where the strength dropped by $33 \%$. The tensile modulus decreases from 7.9 to $7.4 \mathrm{GPa}$ after three reprocessing. The severe loss of tensile strength could result from the significant attrition of glass fiber. Mechanical properties of fiber reinforced composites are closely linked to fiber length[24]. The significant breakages of glass fiber (82-98\% reduction of initial fiber length), during the injection molding process, have been observed by several researchers[25, 26]. The initial fiber length is $8.0 \mathrm{~mm}$ and after the first injection molding the weight average fiber length reduces to 1.83 $\mathrm{mm}$ as shown in Table 2. The average fiber length keeps decreasing at each reprocessing stage and eventually after $3^{\text {rd }}$ recycling the weight average fiber length is $0.46 \mathrm{~mm}$. Besides the fiber shortening, degradation of matrix polymer may decrease the mechanical properties of the composite. High shear stress during injection molding and grinding process causes chain scission of the matrix polymer. The decrement of the molecular weight of polypropylene leads to a poor adhesion between the glass fiber and polypropylene. The mechanical properties in the transverse directions exhibit similar trend as flow direction where VB/PP/MAP sustains tensile properties and GF/PP composite suffers significant deterioration as shown in Figure 4. The different mechanical performance in flow and transverse direction is caused by flow field of injection molding. The flow direction has better mechanical properties than transverse direction for both VB/PP and GP/PP where TLCP composite has higher mechanical anisotropy than GF composite. To overcome the anisotropy, processes such as compression molding, blowing molding and injection compression molding can be used.

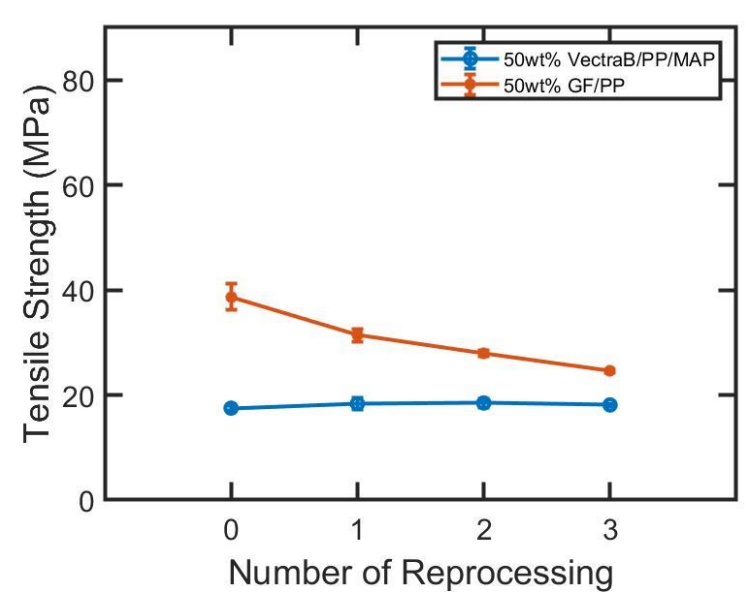

Figure 4. Tensile strength of recycled VB/PP/MAP and $\mathrm{GF} / \mathrm{PP}$ in transverse direction 
Table 2. Average fiber length (mm) of recycled GF/PP

\begin{tabular}{cllll}
\hline No. Recycle & 0 & 1 & 2 & 3 \\
\hline $\mathrm{L}_{\mathrm{n}}(\mathrm{mm})$ & 0.792 & 0.487 & 0.412 & 0.346 \\
$\mathrm{~L}_{\mathrm{w}}(\mathrm{mm})$ & 1.829 & 0.644 & 0.548 & 0.465 \\
\hline
\end{tabular}

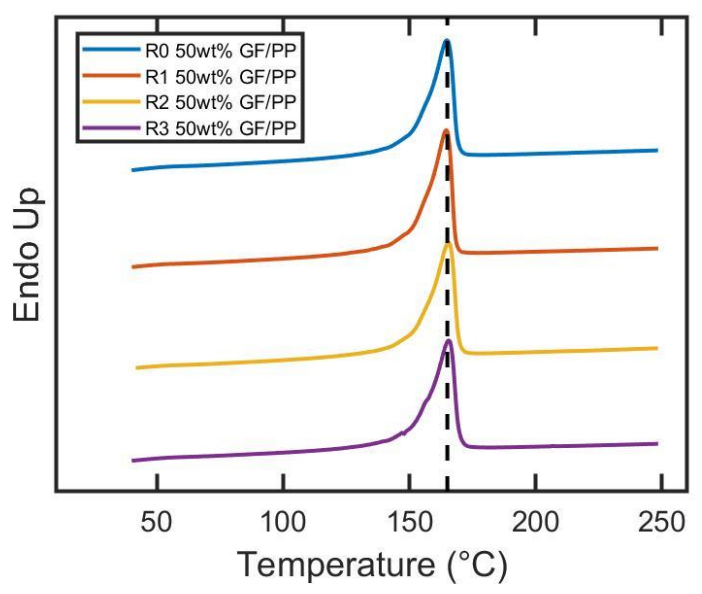

Figure 5. DSC first heating curve of GF/PP composites

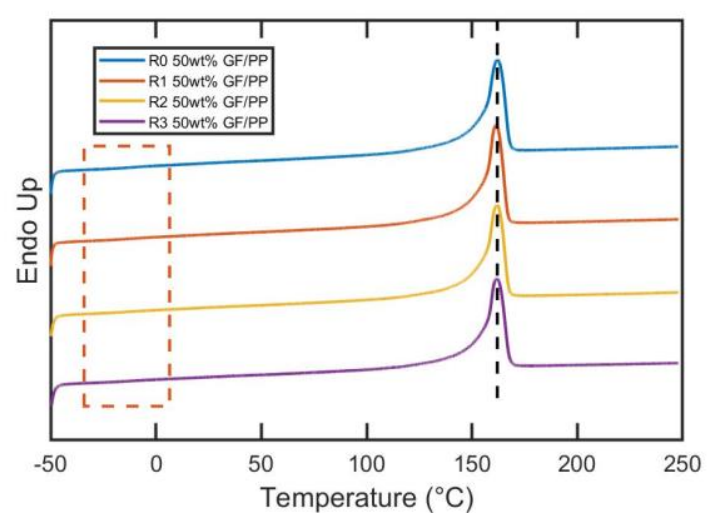

Figure 6. DSC second heating curve of GF/PP composites

\section{Thermal Properties of Recycled Composites}

To examine the effect of mechanical recycling on thermal properties such as glass transition temperature $\left(T_{\mathrm{g}}\right)$, melting point $\left(T_{\mathrm{m}}\right)$ and crystallization temperature $\left(T_{\mathrm{c}}\right)$ were measured by DSC. DSC curves of first and second heating of GF/PP composite are shown in Figure 5 and Figure 6. $T_{\mathrm{g}}$ value of all recycled GF/PP is approximately $12^{\circ} \mathrm{C}$ and the change of $T_{\mathrm{m}}$ with respect to the recycling number was very small. The degree of crystallinity $\left(X_{\mathrm{c}}\right)$ of
GF/PP was determined with the enthalpy of melting $\left(\Delta H_{\mathrm{m}}\right)$ and $\Delta H_{m}^{0}=207 \mathrm{~J} / \mathrm{g}[15]$. The $X_{\mathrm{c}}$ and $T_{\mathrm{m}}$ of recycled GF/PP are listed in Table 3. A very small fluctuation of crystallinity was observed (from 25.28 to $23.87 \%$ ), which means the effect on crystallinity on mechanical properties is negligible.

Table 3. Thermal Properties of recycled GF/PP

\begin{tabular}{lll}
\hline Sample & $T_{\mathrm{m}}\left({ }^{\circ} \mathrm{C}\right)-\mathrm{PP}$ & $X_{\mathrm{c}}(\%)$ \\
\hline $\mathrm{Re} 0-\mathrm{GF} / \mathrm{PP}$ & 164.72 & 25.28 \\
$\mathrm{Re} 1-\mathrm{GF} / \mathrm{PP}$ & 164.45 & 25.51 \\
$\mathrm{Re} 2-\mathrm{GF} / \mathrm{PP}$ & 165.48 & 23.77 \\
$\mathrm{Re} 3-\mathrm{GF} / \mathrm{PP}$ & 165.64 & 23.87 \\
\hline
\end{tabular}

\section{Conclusions}

In this work, TLCP and GF reinforced PP have been recycled and TLCP/PP demonstrates superior recyclability over GF/PP due to the generation of fibrils during mold filling steps. The fiber shortening has a major impact on mechanical properties of GF/PP, which is induced by repeated injection molding and grinding. The thermal properties of TLCP/PP and GF/PP have been analyzed by DSC. The results show that injection molding and grinding does not impact the glass transition temperature, melting temperature and crystallinity of recycled composites.

In continuation of this work, the influence of mechanical recycling on rheological, thermal stability and thermo-mechanical properties will be analyzed in order to gain full understanding about the impact of recycling on the various properties of TLCP and GF composites.

\section{Acknowledgements}

The authors would like to thank SABIC and Celanese for supplying all the materials in this study.

\section{Reference}

1. Masuelli, M. A., Introduction of fibrereinforced polymers- polymers and composites: Concepts, properties and processes. In Fiber reinforced polymers-the technology applied for concrete repair, IntechOpen: 2013.

2. Geyer, R.; Jambeck, J. R.; Law, K. L., Production, use, and fate of all plastics ever made. Science advances 2017, 3, e1700782. 
3. Han, J. Y.; Chen, T.; Mu, Q.; Baird, D. G., Thermotropic liquid crystalline polymer reinforced polypropylene composites enhanced with carbon nanotubes for use in fused filament fabrication. Polymer composites 2021.

4. Chen, T.; Han, J. Y.; Okonski, D. A.; Kazerooni, D.; Ju, L.; Baird, D. G., Thermotropic liquid crystalline polymer reinforced polyamide composite for fused filament fabrication. Additive Manufacturing 2021, 40, 101931.

5. Chen, T., The influence of recycling on thermotropic liquid crystalline polymer and glass fiber composites. 2021.

6. Chen, T. Generation of recyclable liquid crystalline polymer reinforced composites for use in conventional and additive manufacturing processes. Virginia Tech, 2021.

7. Han, J. Y.; Chen, T.; Baird, D. G., Generation of nylon copolymer reinforced with carbon nanotubes and thermotropic liquid crystalline polymers for use in fused filament fabrication. Polymer composites 2021, 42, 4328-4341.

8. Chen, T.; Kazerooni, D.; Ju, L.; Okonski, D. A.; Baird, D. G., Development of recyclable and highperformance in situ hybrid tlcp/glass fiber composites. Journal of Composites Science 2020, 4, 125.

9. Krishnaswamy, R. K.; Baird, D. G., Wholly thermoplastic composites from woven preforms based on nylon-11 fibers reinforced in situ with a hydroquinone-based liquid crystalline polyester. Polymer composites 1997, 18, 526-538.

10. Huang, J.; Baird, D. G., Injection molding of polypropylene reinforced with thermotropic liquid crystalline polymer microfibrils. Part iii:

Combination of glass and tlcp. Journal of Injection Molding Technology 2002, 6, 187.

11. Sabol, E. A.; Handlos, A. A.; Baird, D. G., Composites based on drawn strands of thermotropic liquid-crystalline polymer reinforced polypropylene. Polymer composites 1995, 16, 330345.

12. Kalfon-Cohen, E.; Marom, G.; Wachtel, E.; Pegoretti, A., Characterization of drawn monofilaments of liquid crystalline polymer/carbon nanoparticle composites correlated to nematic order. Polymer 2009, 50, 1797-1804.

13. Wagner, H.; Nairn, J.; Detassis, M., Toughness of interfaces from initial fiber-matrix debonding in a single fiber composite fragmentation test. Applied Composite Materials 1995, 2, 107-117.

14. Oliveux, G.; Dandy, L. O.; Leeke, G. A., Current status of recycling of fibre reinforced polymers: Review of technologies, reuse and resulting properties. Progress in Materials Science 2015, 72, 61-99.

15. Colucci, G.; Simon, H.; Roncato, D.; Martorana, B.; Badini, C., Effect of recycling on polypropylene composites reinforced with glass fibres. Journal of Thermoplastic Composite Materials 2017, 30, 707-723.

16. Chen, T.; Mansfield, C. D.; Ju, L.; Baird, D. G., The influence of mechanical recycling on the properties of thermotropic liquid crystalline polymer and long glass fiber reinforced polypropylene. Composites Part B: Engineering 2020, 200, 108316.

17. Seo, Y.; Ninh, T. H.; Hong, S. M.; Kim, S.; Kang, T. J.; Kim, H.; Kim, J., In situ compatibilizerreinforced interface between a flexible polymer (a functionalized polypropylene) and a rodlike polymer (a thermotropic liquid crystalline polymer).

Langmuir 2006, 22, 3062-3067.

18. Nguyen, B. N.; Bapanapalli, S. K.; Holbery, J. D.; Smith, M. T.; Kunc, V.; Frame, B. J.; Phelps, J. H.; Tucker III, C. L., Fiber length and orientation in long-fiber injection-molded thermoplastics-part i: Modeling of microstructure and elastic properties. Journal of composite materials 2008, 42, 1003-1029. 19. Qin, Y.; Brydon, D.; Mather, R.; Wardman, R., Fibres from polypropylene and liquid crystal polymer blends: 3 . A comparison of polyblend fibres containing vectra a900, vectra b950 and rodrun Ic3000. Polymer 1993, 34, 3597-3604.

20. Postema, A.; Fennis, P., Preparation and properties of self-reinforced polypropylene/liquid crystalline polymer blends. Polymer 1997, 38, 55575564.

21. O'Donnell, H. J.; Baird, D. G., In situ reinforcement of polypropylene with liquidcrystalline polymers: Effect of maleic anhydridegrafted polypropylene. Polymer 1995, 36, 31133126.

22. Tjong, S., Structure, morphology, mechanical and thermal characteristics of the in situ composites based on liquid crystalline polymers and thermoplastics. Materials Science and Engineering: R: Reports 2003, 41, 1-60. 
23. Datta, A.; Chen, H.; Baird, D. G., The effect of compatibilization on blends of polypropylene with a liquid-crystalline polymer. Polymer 1993, 34, 759-766.

24. Thomason, J., The influence of fibre length and concentration on the properties of glass fibre reinforced polypropylene: 5 . Injection moulded long and short fibre pp. Composites Part A: Applied Science and Manufacturing 2002, 33, 1641-1652. 25. Eriksson, P. A.; Albertsson, A. C.; Boydell, P.; Prautzsch, G.; Månson, J. A., Prediction of mechanical properties of recycled fiberglass reinforced polyamide 66. Polymer composites 1996, 17, 830-839.

26. Bernasconi, A.; Davoli, P.; Rossin, D.; Armanni, C., Effect of reprocessing on the fatigue strength of a fibreglass reinforced polyamide. Composites Part A: Applied Science and Manufacturing 2007, 38, 710-718. 